\title{
Do you have NIH funding? Then read this.
}

In the "Policy on enhancing public access to archived publications resulting from NIH-funded research," the NIH requests that all publications resulting from primary research supported by NIH grants be deposited in PubMed Central (PMC), the online repository of the National Library of Medicine. The NIH requests that all manuscripts accepted for publication after May 2, 2005 be deposited in PMC, and that those manuscripts be made freely available to the public within 12 months of publication. The JCI supports this policy: we will continue to make all content freely available in PMC immediately upon publication, and the entire JCI archive is freely available through PMC.

In the "Policy on enhancing public access to archived publications resulting from NIH-funded research," the NIH requests (but does not require) that investigators receiving NIH funding voluntarily deposit a copy of their primary research in the National Library of Medicine's repository, PubMed Central (PMC), after the manuscript has been accepted for publication in a peer-reviewed journal (1). The reasons for the new policy are 3-fold, according to the February 9, 2005, report in the Federal Register (1). First, the NIH hopes to create a secure and long-standing archive to ensure the permanent preservation of $\mathrm{NIH}$-funded research findings. Second, they seek to bring together research articles into a searchable compendium that they can use to monitor where scientific interest lies and determine where their funding efforts should be focused. And third, the NIH wants this free archive to extend the reach of research it funds to everyone, everywhere.

Since May 2, 2005, researchers have been able to deposit their final accepted manuscripts in PMC using the interface at http://nihms.nih.gov/ and can link their manuscripts to the NIH grant(s) that supported the work. Manuscripts deposited by authors are not made available to the public through PMC until after the final version is published by the journal, and authors have the ability to specify how long after publication their article should be held before it becomes freely available to the public. The NIH requests that all NIH- funded research be made available within 12 months of the final publication date, and wants to link authors' works to the appropriate grants to give the NIH an ata-glance view of its grant activity. According to the policy, this process will alleviate grant reporting procedures by effectively creating a paperless grants management process. While concerns have been raised that this policy could lead to duplicate entries into the scientific record - and confusion about which version to cite - such problems should not occur with articles published in the JCI, since all JCI content is deposited into PMC and is freely available immediately upon publication.

The NIH policy has no effect on copyright; depositing manuscripts in PMC does not entail transferring any copyright to PMC or the NIH. Authors should continue to adhere to the publishing journal's copyright policy. In the case of the JCI, authors of accepted manuscripts are required to assign copyright to the American Society for Clinical Investigation (ASCI), the publisher of the JCI. While the ASCI holds copyright to all published material (except those works wherein an author is a US government employee, and thus no copyright exists), it provides unrestricted access to all $J C I$ content and permits unrestricted use of all JCI content for noncommercial, nonprofit, educational purposes.

How will this new policy change scientific publishing? The NIH claims that it won't make much of a splash. As the proposed policy was open to comment for several months, the question of whether this would cause decreased subscription revenue to journals did arise. The NIH's response was that since publications from NIH-funded research represent only about $10 \%$ of the articles indexed by PubMed (a separate database of citations and abstracts that links to publishers' pages), most libraries and individuals would not use the content from PMC to replace their subscriptions (1). They estimate that NIH-supported research represented 60,000-65,000 publications in 2003 alone; only $1 \%$ of journals derive more than half their content from NIH-supported research (1). The JCI is included in that $1 \%$, with approximately $50 \%$ of published research being supported by NIH grants. Even so, since the JCI has been a free-access journal since 1996, this policy is not likely to affect the Journal at all. And while the ASCI is among the many publishers concerned about government policies affecting the future of scientific publishing and nonprofit societies, we support the NIH in its efforts to preserve the scientific record and make it widely available.

Issues of central archive and improved grants management process aside, this policy was brought about to make the results of government-supported research available to the general public: the taxpayers who supported the research. But will most taxpayers care? Will this policy really benefit the general public or speed scientific discoveries? Only time, and taxpayers, will tell. But the JCI has long been committed to free access, and we will continue to make our content freely available to all.

\section{Ushma S. Neill Executive Editor}

\section{Karen Kosht Managing Director}

\footnotetext{
1. National Institutes of Health. 2005. Policy on enhancing public access to archived publications resulting from NIH-funded research. Federal Register. 70:6891-6900
} 